\title{
Expression of the immune checkpoint receptor TIGIT in Hodgkin's lymphoma
}

Wenchao $\mathrm{Li}^{1 \dagger}$, Niclas C. Blessinn ${ }^{1 \dagger}$, Ronald Simon ${ }^{1 *}$ (D), Martina Kluth ${ }^{1}$, Kristine Fischer $^{2}$, Claudia Hube-Magg ${ }^{1}$, Georgia Makrypidi-Fraune', Björn Wellge ${ }^{3}$, Tim Mandelkow ${ }^{1}$, Nicolaus F. Debatin ${ }^{1}$, Laura Pott ${ }^{1}$, Doris Höflmayer ${ }^{1}$,

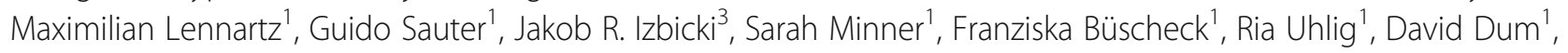
Till Krech ${ }^{1}$, Andreas M. Luebke ${ }^{1}$, Corinna Wittmer ${ }^{1}$, Frank Jacobsen ${ }^{1}$, Eike Burandt ${ }^{1}$, Stefan Steurer ${ }^{1}$,

Waldemar Wilczak ${ }^{1}$ and Andrea Hinsch ${ }^{1}$

\begin{abstract}
Hodgkin's lymphoma $(\mathrm{HL})$ is characterized by a high background of inflammatory cells which play an important role for the pathogenesis of the disease. T cell immunoreceptor with Ig and ITIM domains (TIGIT) is an inhibitory immune checkpoint receptor and a putative target for novel immunotherapies. To study patterns of TIGIT expression in the T cell background surrounding malignant cells including Hodgkin cells, Reed-Sternberg cells and histiocytic cells, a microenvironment (ME) tissue microarray (TMA) was constructed from tissue punches measuring $2 \mathrm{~mm}$ in diameter obtained from formalin-fixed tissue samples of Hodgkin's lymphoma lymph nodes $(n=40)$ and normal human tonsil $(n=2)$. The ME-TMA was stained by brightfield and fluorescence multiplex immunohistochemistry $(\mathrm{IHC})$ to evaluate expression levels of TIGIT and PD-1 as well as standard lymphocyte markers (CD3, CD8, CD4, FOXP3) in the lymphocytic background. All analyzed cases of HL contained 9-99\% (median: 86\%) of TIGIT lymphoid cells. In general, TIGIT localized to the same cells as PD-1. Strikingly, expression levels of TIGIT and PD-1 were highly variable among the analyzed samples. Highest levels of TIGIT and PD-1 were found in one sample of nodular lymphocytic-predominant HL (NLPHL). In conclusion, TIGIT expression is highly variable between patients with Hodgkin's lymphoma. Our results encourage further studies evaluating the role of TIGIT as a target for immunotherapies in Hodgkin's lymphoma.
\end{abstract}

Keywords: TIGIT, PD-1, Immune checkpoint, Hodgkin's lymphoma

\section{Introduction}

Hodgkin's lymphoma $(\mathrm{HL})$ is a malignant transformation of B cell origin that accounts for about $20-30 \%$ of lymphomas in Western societies [1-3]. Although the majority of Hodgkin's lymphoma patients are curable with a multi-agent chemotherapy and/ or radiotherapy protocol, about $10-20 \%$ of patients develop therapy refractory disease [4]. A characteristic feature of HL is the presence of few malignant cells, including Hodgkin cells, Reed-Sternberg cells and histiocytic cells, in a high background of inflammatory cells. Current clinical trials provide first evidence that immune checkpoint inhibitors targeting the

\footnotetext{
* Correspondence: R.Simon@uke.de

${ }^{+}$Wenchao Li and Niclas C. Blessin contributed equally to this work. 'Department of Pathology, University Medical Center Hamburg-Eppendorf, Martinistr. 52, 20246 Hamburg, Germany

Full list of author information is available at the end of the article
}

PD-1/PD-L1 axis may hold promise in these refractory or relapsed Hodgkin's lymphomas [5-7].

$\mathrm{T}$ cell immunoglobulin and ITIM domain (TIGIT), a co-inhibitory transmembrane glycoprotein of the poliovirus receptor (PVR)/-nectin superfamily, is another interesting candidate for novel checkpoint therapies $[8,9]$. Using multiplex fluorescence immunohistochemistry, we have recently shown that TIGIT typically co-localizes with PD-1 on CD8+ cytotoxic T cells, CD4+ T helper cells and FOXP3 regulatory $\mathrm{T}$ cells [10]. Tumor associated lymphocytes expressing TIGIT have so far been demonstrated in acute myeloid leukemia, non-small cell lung cancer, colorectal carcinoma and melanoma [11-13]. Although the downstream signaling cascade of TIGIT has not been clarified, there is evidence that TIGIT negatively regulates $\mathrm{T}$ cell activity through downregulation of $\mathrm{T}$ cell receptor expression $[8,14,15]$. In mouse models and ongoing clinical studies, blockade or ablation of TIGIT, alone or in 
combination with blockade of programmed cell death protein (PD-1), can restore tumor suppressive effects [11, 12, 16-18]. These findings indicate that TIGIT, similar to PD-1, has a crucial role in inhibiting the tumor-directed immune response and, thus, might be a suitable and relevant target for novel immune-modulating therapies. Several drugs targeting TIGIT are currently under development [19].

As to yet, data on the possible role of TIGIT in Hodgkin's lymphoma are lacking. Here, we made use of a microenvironment (ME) tissue microarray (TMA) that was constructed from $2 \mathrm{~mm}$ tissue punches each from 40 Hodgkin's lymphomas and studied patterns of TIGIT and PD-1 expression by means of conventional bright field and multiplex fluorescence immunohistochemistry.

\section{Material and methods}

\section{Tissues}

Formalin-fixed paraffin-embedded tissue samples from 40 patients with Hodgkin's lymphoma were selected from the archives of the institute of Pathology of the University Medical Center Hamburg-Eppendorf, Germany. The selection included 30 patients diagnosed with nodular sclerosis classical HL (NSCHL), 7 patients with mixed cellularity classical HL (MCCHL), one patient with lymphocyte rich classical HL (LRCHL), and one patient with nodular lymphocyte predominance HL (NLPHL). The histological subtype was undetermined for another patient.

\section{Microenvironment (ME) TMA construction}

A pathologist reviewed all cases and selected areas containing Hodgkin and Reed-Sternberg cells for TMA construction. A single tissue punch measuring $2 \mathrm{~mm}$ in diameter was taken from each donor tissue block to capture the lymphocytic background adjacent to the malignant cells. In addition, two punches of normal human tonsil were added to the TMA as a reference tissue for fluorescence measurement normalization. The usage of archived diagnostic left-over tissues for manufacturing of tissue microarrays and their analysis for research purposes as well as patient data analysis has been approved by local laws (HmbKHG, $\$ 12,1$ ) and by the local ethics committee (Ethics commission Hamburg, WF-049/09).

\section{Immunohistochemistry}

Freshly cut $4 \mu \mathrm{m}$ tissue sections were used for immunohistochemistry (IHC) analyses. For brightfield IHC, tissue sections were dewaxed and incubated in an autoclave for $5 \mathrm{~min}$ at $121^{\circ} \mathrm{C}$ in Tris-EDTA pH 7.8 antigen retrieval solution prior to blocking of endogenous peroxidase and incubation of the primary antibody (Dianova mouse anti TIGIT, clone TG-1,1:70). Bound antibody was detected with the DAB-kit (DAKO, Santa Clara, United States) and slides were counterstained and sealed in EUKITT ${ }^{\circ}$. For fluorescence multiplex $\mathrm{IHC}$, the $\mathrm{Opal}^{\mathrm{Tm}}$ dye kit (Cat. \#OP7DS1001KT, Perkin Elmer, Waltham, Massachusetts, United States) was used. The experimental procedure was performed according to the manufacturer's instructions. Slides were initially boiled in a microwave oven for $15 \mathrm{~min}$ at $100{ }^{\circ} \mathrm{C}$ for antigen retrieval. Three different primary antibodies were combined with DAPI staining in each experiment. One circle of antibody staining included peroxidase blocking, application of the primary antibody, detection with a secondary HRP-conjugated antibody, fluorescence dye detection, and removal of the bound antibodies by microwave treatment $\left(15 \mathrm{~min}\right.$ at $\left.100^{\circ} \mathrm{C}\right)$. This cycle was repeated two times for the remaining antibodies. Slides were subsequently counterstained with diamidino-2-phenylindole (DAPI) and mounted in antifade solution. Details on the used antibodies, antibody retrieval procedures and $\mathrm{Opal}^{\mathrm{Tm}}$ dyes are given in Table 1.

\section{Quantification of TIGIT and PD-1 expression}

Digital images of multiplex immunofluorescence stainings were acquired using a Leica Aperio VERSA 8 automated epifluorescence microscope. For initial image acquisition, exposure time was manually adjusted for each fluorochrome to minimize auto fluorescence.

Table 1 List of the used antibodies, antigen retrieval (AR), dilutions and Opal ${ }^{\mathrm{TM}}$ dyes

\begin{tabular}{|c|c|c|c|c|c|c|c|}
\hline \multirow[b]{2}{*}{ Antibody } & \multirow[b]{2}{*}{ Target } & \multicolumn{2}{|c|}{ Bright field } & \multicolumn{4}{|c|}{ Fluorescence } \\
\hline & & $\overline{\mathrm{AR}}$ & $\overline{\text { Dilution }}$ & $\overline{\mathrm{AR}}$ & Dilution & Order $^{1}$ & Dye \\
\hline DAKO \#IR503 & CD3 & $\mathrm{pH} 9$ & $1: 1$ & $\mathrm{pH} 9$ & $1: 1$ & $1 \mathrm{st}$ & Opal 520 \\
\hline DAKO \#IR649 & CD4 & $\mathrm{pH} 9$ & $1: 1$ & $\mathrm{pH} 9$ & $1: 1$ & $1 \mathrm{st}$ & Opal 520 \\
\hline DAKO \#IR623 & CD8 & $\mathrm{pH} 9$ & $1: 1$ & $\mathrm{pH} 9$ & $1: 1$ & $1 s t^{a}$ & Opal $520^{b}$ \\
\hline BioLegend \#320102 & FOXP3 & $\mathrm{pH} 9$ & $1: 50$ & $\mathrm{pH} 9$ & $1: 50$ & $1 \mathrm{st}$ & Opal 520 \\
\hline DAKO \#IR604 & CD20 & $\mathrm{pH} 9$ & $1: 1$ & $\mathrm{pH} 9$ & $1: 10$ & $1 s t^{a}$ & Opal $520^{\mathrm{b}}$ \\
\hline Dianova \#DIA-TG1 & TIGIT & $\mathrm{pH} 7.8$ & $1: 70$ & $\mathrm{pH} 9$ & $1: 150$ & 2nd & Opal 570 \\
\hline Abcam \#ab52587 & PD-1 & $\mathrm{pH} 6$ & $1: 50$ & $\mathrm{pH} 6$ & $1: 50$ & $3 r d$ & Opal 690 \\
\hline
\end{tabular}

Order $^{1}$, order refers to the sequence of antibodies in multiplex fluorescence immunohistochemistry experiments

a antibody was used at third position when stained in combination with CD3, CD4

${ }^{b}$ with Opal ${ }^{\mathrm{TM}} 690$ dye 
Subsequently, a threshold for positive staining was defined as follows: The fluorescence intensity of each antibody was measured in 50 to 200 cells of a cell type with known lack of expression and the fluorescence value of the cell with highest "false positive" measurement was used to define the cutoff value for positive expression.

After slide scanning, image analysis was performed using Image Scope software package (Leica Microsystems Wetzlar, Germany). Image analysis included segmentation of individual cells and subsequent measurement of the fluorescence intensity (concentration as dye intensity per $\mu \mathrm{m}^{2}$ ). Tissue areas for analysis were manually defined and typically included between 18,000 and 30,000 cells. Fluorescence intensity values were recorded for each fluorochrome in each cell. The average fluorescence intensity of all cells of the same compartment from all measured areas was calculated and used for comparisons. Because staining intensity largely depends on antibody specification and staining protocols we sought to introduce a reference tissue for staining normalization to our experiments. We selected two samples of tonsil tissue, which were placed on the same TMA along with the study samples. In our previous study [10], we found that cells located within the germinal centers of tonsil tissues had the highest TIGIT and PD-1 expression level of all human normal tissues. We calculated an average from approximately 1000 lymphocytes located at the periphery of the germinal centers
(500 from each tonsil), considered this expression level as $100 \%$ and used it as the reference value to estimate the staining intensity of TIGIT and PD-1 on CD3 positive cells in the lymphocytic background of HL (relative expression, RE). In addition, the expression level of CD3 was used as an immunoreactivity control to indicate potential fixation or processing artefacts.

\section{Statistics}

JMP Pro 12 software package (SAS Institute Inc., NC, USA) analysis of variance (ANOVA) test was employed to calculate compartment specific expression differences of PD-1 and TIGIT in tissue samples.

\section{Results}

TIGIT brightfield immunohistochemistry

All $40 \mathrm{HL}$ included in this study were successfully analyzed and showed detectable TIGIT staining in 9-99\% (Median: 86\%) of the lymphocytic background cells by means of conventional bright field immunohistochemistry. Representative images are shown in Fig. 1. By manual inspection of the stained slide, highest staining intensities were found in a case of NLPHL. Additional experiments with serial dilutions of the TIGIT antibody confirmed the presence of $\mathrm{T}$ cells with extraordinary high levels of TIGIT expression (i.e. exceeding that of normal human tonsils germinal centers) particularly in NLPHL (Additional file 1:

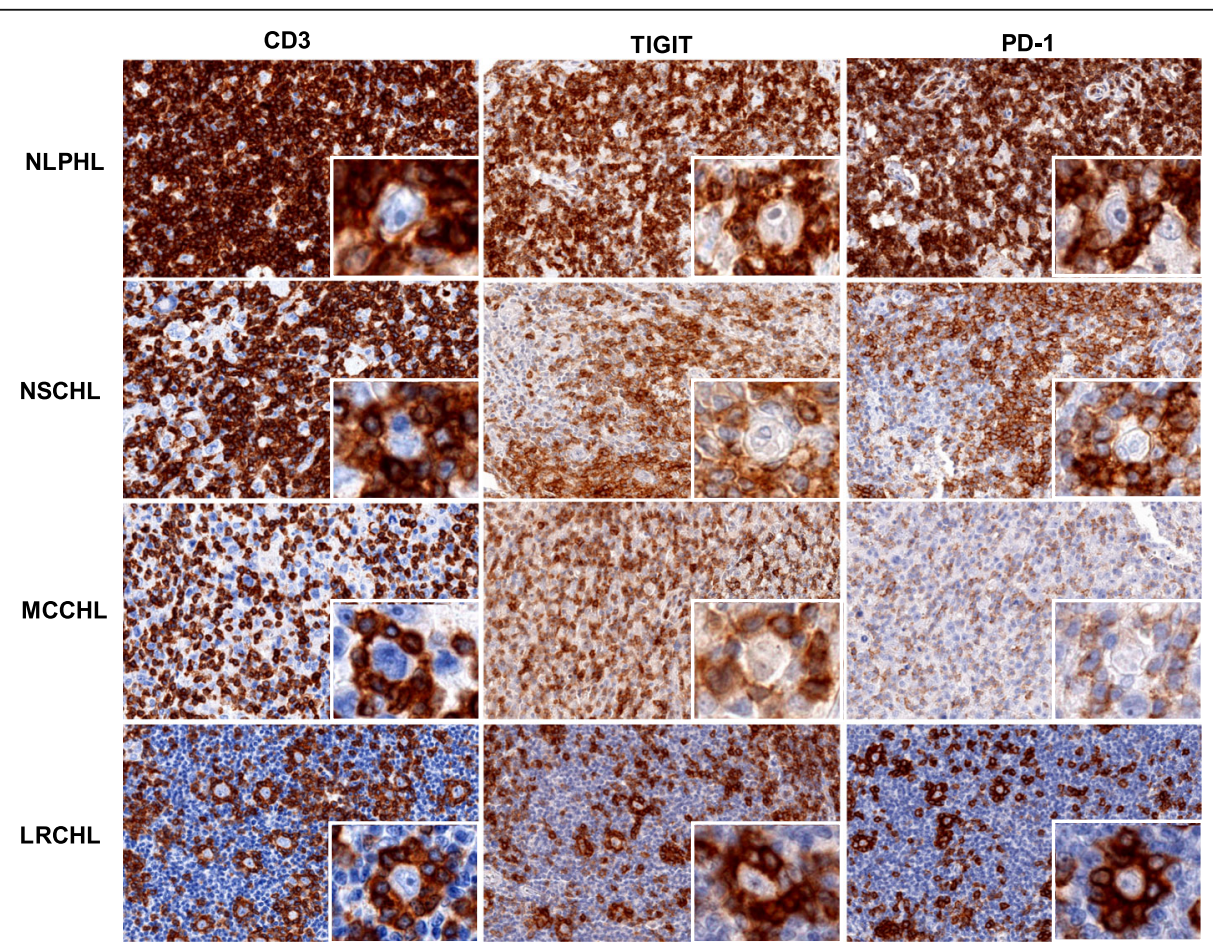

Fig. 1 Representative images of CD3, TIGIT and PD-1 staining in nodular lymphocyte predominance HL (NLPHL), nodular sclerosis classical HL (NSCHL), mixed cellularity classical HL (MCCHL) and lymphocyte rich classical HL ( $\mathrm{LRCHL}$ ). Insets show magnifications of Hodgkin and ReedSternberg cells surrounded by TIGIT and PD-1 expressing CD3 positive T cells 
Figure S1). Also, staining intensity of the $\mathrm{T}$ cell rosettes surrounding malignant (HRS and LP) cells in NLPHL and in LRCHL appeared somewhat stronger as compared to scattered CD3 positive lymphocytes in the vicinity (Fig. 1).

\section{Multiplex fluorescence immunohistochemistry}

We performed multiplex fluorescence immunohistochemistry to unravel the immune cell types expressing TIGIT and to quantify TIGIT expression among individual patients. TIGIT was virtually undetectable on CD20 positive $\mathrm{B}$ lymphocytes but expressed on a large fraction (70\%) of CD3 positive $\mathrm{T}$ lymphocytes. Further analysis revealed that TIGIT positive $\mathrm{T}$ cell subtypes included CD8 cytotoxic $\mathrm{T}$ cell, CD4 helper $\mathrm{T}$ cells and FOXP3 regulatory $\mathrm{T}$ cells (Fig. 2). Interestingly, relative expression (RE) levels of TIGIT were highly variable among individual patients and different HL subtypes. When compared to the RE level found in the reference tissue (normal human tonsil germinal center periphery set to $100 \% \mathrm{RE}$ ), TIGIT RE in CD3 positive $\mathrm{T}$ cells ranged between 1 and $122 \%$ in different patients. Most patients had TIGIT expression levels equaling less than $50 \%$ of the reference tissue. Again, highest TIGIT expression (122\%) was seen in one case of nodular lymphocyte-predominant HL (NLPHL, Fig. 3).

\section{Relationship between TIGIT and PD-1 expression}

To estimate the fraction of CD3 positive T cells expressing TIGIT only, PD-1 only, both, or none of the two, we focused on the largest HL subtype $(n=30 \mathrm{NSCHL})$. On average across all patients, it showed that the majority (68\%) of T cells had co-expression of TIGIT and PD-1, while isolated positivity for TIGIT and PD-1 was seen in only 14 and $5 \%$. The remaining $13 \% \mathrm{~T}$ cells had neither TIGIT nor PD-1 expression (Fig. 4). Fluorescence measurements further confirmed presence of $\mathrm{T}$ cells with very high levels of TIGIT and PD-1 expression in NLPHL. For example, the top $10 \%$ of TIGIT and PD-1 positive T cells averaged $241 \%$ RE and 408\% RE, respectively.

\section{Discussion}

The data from this study demonstrate that TIGIT is frequently expressed in cells of the lymphocytic background accompanying HL and that the frequency and intensity of TIGIT expression varies markedly between individual patients.

All $40 \mathrm{HL}$ analyzed in our study showed detectable TIGIT expression in all types of CD3 positive $\mathrm{T}$ cells including $\mathrm{CD} 8$ cytotoxic $\mathrm{T}$ cells, $\mathrm{CD} 4$ positive $\mathrm{T}$ helper cells, and FOXP3 positive regulatory $\mathrm{T}$ cells. This corresponds to the situation in other normal and inflamed tissues, where we also found that TIGIT expression was largely limited to these three major types of immune cells. In this earlier study, we also found that TIGIT expression often paralleled PD-1 expression in these cells. It was therefore expected that a large fraction (more than $80 \%$ ) of TIGIT positive T cells also expressed PD-1 in our study. In normal lymph nodes and tonsils, TIGIT and PD-1 co-expression was found in 50-99\% of $\mathrm{T}$ cells depending on the analyzed $\mathrm{T}$ cell subtype [10]. These findings are in line with a study describing that TIGIT (and PD-1) are constitutively expressed on about one third of circulating FOXP3 positive regulatory $\mathrm{T}$ cells and highly upregulated on regulatory $\mathrm{T}$ cells in an inflamed microenvironment $[20,21]$. This suggests that the lymphocytic background of HL is affected by the same immunoregulatory mechanisms that also apply in inflammatory and cancerous tissues.

In contrast to many other studies that reported PD-1 staining in $20-60 \%$ of classical HL [22-27], we detected PD-1 positive lymphocytes in all analyzed cases. Some of the discrepant findings may be related to different definitions of PD-1 positivity in earlier work, for example studies where PD-1 positivity was assumed only when
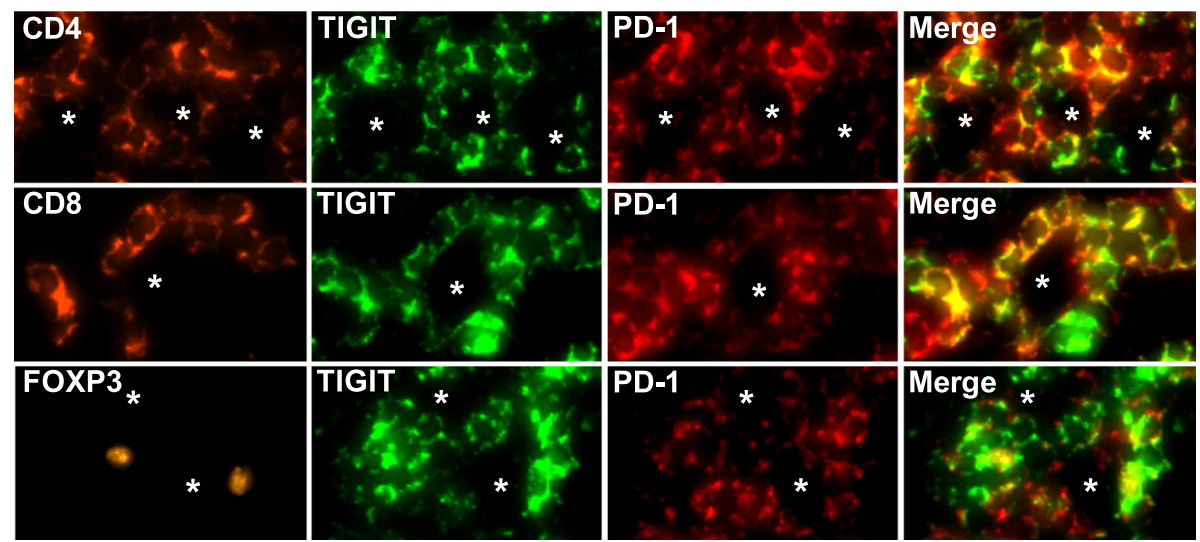

Fig. 2 Representative multiplex immunofluorescence images showing TIGIT and PD-1 staining in CD4 positive T helper cells (top panel), CD8 positive cytotoxic T cells (middle panel) and FOXP3 regulatory T cells (bottom panel) 


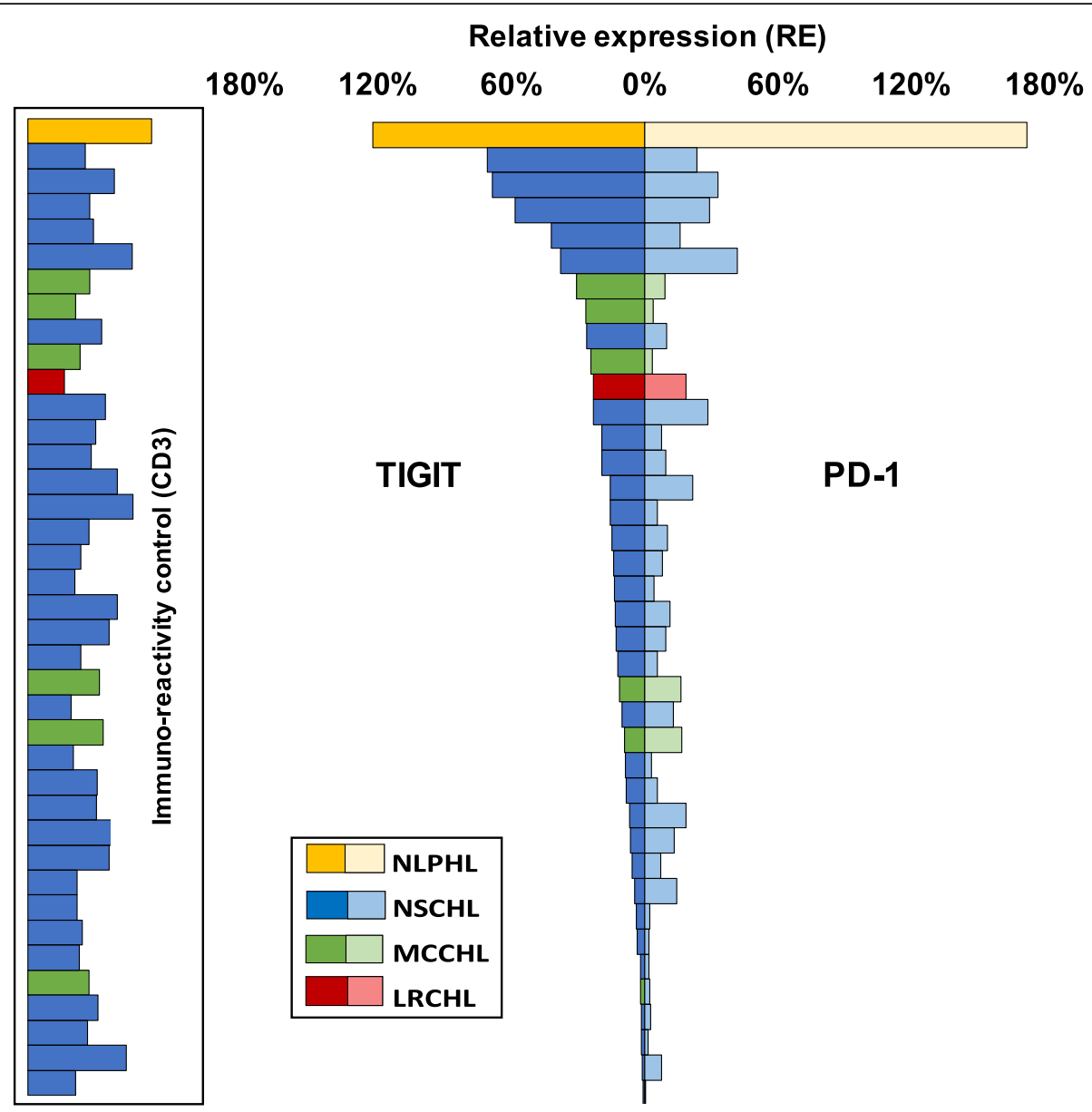

Fig. 3 Variability of TIGIT (left) and PD-1 (right) expression in CD3 positive T cells in the lymphocytic background of different types of Hodgkin's lymphoma (HL). Relative expression refers to the fluorescence measurement in normal human tonsils germinal centers set to $100 \%$. NLPHL, nodular lymphocyte predominance $\mathrm{HL}$; NSCHL, nodular sclerosis classical HL; MCCHL, mixed cellularity classical HL; LRCHL, lymphocyte rich classical HL. Bars in the box indicate expression levels of CD3 as an indicator of immunoreactivity of the analyzed tissue samples

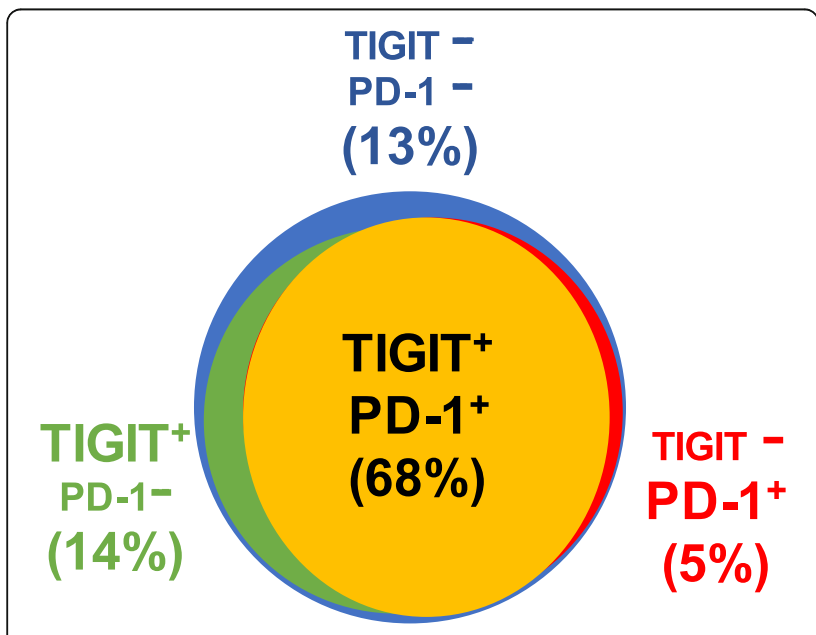

Fig. 4 Average fractions of CD3 positive T cells expressing TIGIT only (green), PD-1 only (red), both (yellow) or neither one (blue) in 30 cases of nodular lymphocyte predominance HL (NSCHL) more than $20 \%$ of cells [27] or more than 23 cells $/ \mathrm{mm}^{2}$ [26] had detectable PD-1 staining. While it is obviously impossible to explain all discrepant reports, we previously found that certain levels of TIGIT and PD-1 expression are characteristic features of lymphatic infiltrations in a wide range of inflamed and cancerous tissue [10].

The fluorescence approach enabled us to quantify the expression level of TIGIT and PD-1. We have recently shown that highest physiological TIGIT and PD-1 expression was found in follicular $\mathrm{T}$ helper cells residing at the periphery of germinal centers in lymph nodes and tonsils [10]. Given this consistently high expression levels and because of the easiness to identify follicular $\mathrm{T}$ cells, we have used these cells as a reference to compare the variable TIGIT and PD-1 expression of T cells located in other tissue areas. Accordingly, all measured intensity levels that were lower than $100 \%$ do, however, not imply reduced TIGIT and PD-1 expression of the respective cells. We 
recorded a stunning degree of TIGIT and PD-1 expression level variability across the different HL specimens analyzed. The much less variable expression levels of CD3 in our cancers argue against relevant fixation related variations in tissue immunoreactivity as a possible reason for the observed interindividual TIGIT expression differences. Biological reasons for the variable expression might include modulation of the immune environment by the Hodgkin and Reed-Sternberg (HRS) cells or the lymphocytic background itself. For example, it has been suggested that the expression of PD-1 on T cells is likely driven by constitutive upregulation of its ligands, PD-L1 and PD-L2, on HRS cells [28] and that HRS cells as well as some leukocytes (e.g. helper and regulatory $\mathrm{T}$ cells or macrophages) [29] can selectively express immunomodulatory proteins connected to PD-1 signaling such as galectin 1 and IL 10 [30, 31]. Hence, it is tempting to speculate that also the level of TIGIT expression may be influenced by regulatory molecules in a similar way as known from PD-1.

Notably, our series of HL included one case of nodular lymphocyte predominant Hodgkin's lymphoma (NLPHL). A unique feature of NLPHL is that the lymphocytic predominant (LP) cells (previously known as "popcorn" cells) arise in a follicular like microenvironment that shares characteristics of germinal centers in lymph nodes and tonsils, such as a high density of follicular $\mathrm{T}$ helper cells $[32,33]$. That highest TIGIT and PD-1 levels in our current study were also found in a HL subtype with a characteristic follicular architecture suggests an important function of these receptors in dense meshworks of leucocytes. Highest levels of TIGIT and PD-1 in tightly packed lymphocytic rosettes surrounding the neoplastic cells fits well to the concept of compensatory downregulation of excessive inflammatory reactions through immune checkpoint upregulation [34, 35]. Exceedingly high PD-1 expression levels in NLPHL has earlier been described and PD-1 expression analysis was suggested as a diagnostic feature for this rare HL subtype [36]. Our fluorescent measurement revealed that the TIGIT and PD-1 expression in individual $\mathrm{T}$ cells could reach 2 to 4 -fold higher levels than those found in normal human tonsils.

Another feature of $\mathrm{HL}$ is that the tumor cells have developed mechanisms to escape the excessive immune -cell infiltration of the host. For example, the cellular landscape of $\mathrm{HL}$ is characterized by a paucity of specific cytotoxic T cells and natural killer (NK) cells [37]. Much hope is, therefore, put on novel therapeutic strategies modulating the immune system and its response to the disease, particularly in heavily treated relapsed or refractory HL where effective therapies are lacking. After promising results were reported from a first clinical trial [5] using the PD-1 inhibitor nivolumab in chemotherapy refractory HL, a number of follow up studies have confirmed the potential of immune checkpoint therapy in this disease [38-41]. Phase I/II studies using nivolumab as a combination or second line therapy in combination with or after anti-CD30 treatment in patients with relapsed and refractory Hodgkin's lymphoma reported over all response rates of $66-85 \%$ [38, 39]. Combining immunotherapies is another option to increase response rates. For example, combination of anti-PD-1 and anti-CTLA4 drugs has demonstrated additive efficacy in melanomas, non-small-cell lung cancer and renal cell carcinoma [6, 42, 43]. At present, several drugs directed against TIGIT are in preclinical pipelines $[17,19]$. In our study, TIGIT and PD-1 expression was found in all analyzed HL and was not limited to a specific subtype. These findings identify $\mathrm{HL}$ as a disease entity where it could be interesting to determine whether TIGIT inhibitors alone or in combination with other immunotherapies and anti-CD30 treatment might be effective. It might be speculated, that the variable levels of TIGIT expression could correspond to variable responses to putative therapies targeting TIGIT.

The large tissue size TMA (ME-TMAs) enable the analysis for large enough tissue areas to study a tumor's microenvironment under perfectly standardized experimental conditions. Having all tissue samples of a study on one glass slide ensures not only fully identical staining procedures for every tissue specimen but also identical section thickness and slide age [44]. This is important for experimental standardization as automated immunostainers are not yet perfectly dealing with the requirements of multiplex fluorescence immunohistochemistry.

In summary, the results of our study identify $\mathrm{HL}$ as a tumor type with frequent but variable expression of immune checkpoint receptors such as TIGIT and PD-1. Patients with HL might benefit from potential future therapies targeting TIGIT alone or in combination with other drugs.

\section{Additional file}

Additional file 1: Figure S1. Serial dilution of the TIGIT antibody in lymph node and a NLPHL. (PDF 6352 kb)

Acknowledgements

We thank Christina Möller-Koop, Inge Brandt, Melanie Witt and Janett Lüttgens for excellent technical assistance.

Funding

None.

Availability of data and materials

All relevant data and materials are included in the manuscript. For the full detailed data, please contact the corresponding author.

Authors' contributions

Conception and design: GS, AH, NB, RS, KF. Development of methodology: WL, NB, RS, GS, KF. Acquisition of data (provided animals, acquired and managed patients, provided facilities, etc.): WL, NB, BW, TM, ND, LP, AH, DH, $M L, J I, S M, F B, R U, D D, T K, A L, C W, F J, E B, S S, W W$. Analysis and interpretation 
of data (e.g., statistical analysis, biostatistics, computational analysis): NB, RS, WL, GS, AH. Writing, review, and/or revision of the manuscript: RS, GS, NB, $\mathrm{AH}$. Administrative, technical, or material support (i.e., reporting or organizing data, tissue processing, antibody development): MK, CH-M, GM-F, DH, ML, J, SM, FB, RU, DD, TK, AL, CW, FJ, EB SS, WW. Study supervision: GS, RS, and AH. All authors read and approved the final manuscript.

\section{Ethics approval and consent to participate}

Ethical approval for this study was obtained from the local ethics board (WF-049/09, Ethics Commission of the Ärztekammer Hamburg).

\section{Consent for publication}

Not applicable.

\section{Competing interests}

The authors declare that they have no competing interests.

\section{Publisher's Note}

Springer Nature remains neutral with regard to jurisdictional claims in published maps and institutional affiliations.

\section{Author details}

'Department of Pathology, University Medical Center Hamburg-Eppendorf, Martinistr. 52, 20246 Hamburg, Germany. ${ }^{2}$ Dianova GmbH, Warburgstrasse 45, 20354 Hamburg, Germany. ${ }^{3}$ Department of General, Visceral and Thoracic Surgery, University Medical Center Hamburg-Eppendorf, Hamburg, Germany.

Received: 11 April 2018 Accepted: 20 November 2018 Published online: 04 December 2018

\section{References}

1. Kuppers R. The biology of Hodgkin's lymphoma. Nat Rev Cancer. 2009;9(1):15-27.

2. Roman E, Smith AG. Epidemiology of lymphomas. Histopathology. 2011;58(1):4-14

3. Erkilic S, Erbagci Z, Kocer NE, Bayazit YA, Camci C. Cutaneous involvement in Hodgkin's lymphoma: report of two cases. J Dermatol. 2004;31(4):330-4.

4. Diehl V, Thomas RK, Re D. Part II: Hodgkin's lymphoma--diagnosis and treatment. Lancet Oncol. 2004;5(1):19-26.

5. Ansell SM, Lesokhin AM, Borrello I, Halwani A, Scott EC, Gutierrez M, Schuster SJ, Millenson MM, Cattry D, Freeman GJ, et al. PD-1 blockade with nivolumab in relapsed or refractory Hodgkin's lymphoma. N Engl J Med. 2015;372(4):311-9.

6. Wolchok JD, Kluger H, Callahan MK, Postow MA, Rizvi NA, Lesokhin AM, Segal NH, Ariyan CE, Gordon RA, Reed K, et al. Nivolumab plus ipilimumab in advanced melanoma. N Engl J Med. 2013;369(2):122-33.

7. Hellmann MD, Rizvi NA, Goldman JW, Gettinger SN, Borghaei H, Brahmer JR, Ready NE, Gerber DE, Chow LQ, Juergens RA, et al. Nivolumab plus ipilimumab as first-line treatment for advanced non-small-cell lung cancer (CheckMate 012): results of an open-label, phase 1, multicohort study. Lancet Oncol. 2017;18(1):31-41.

8. Liu XG, Hou M, Liu Y. TIGIT, a novel therapeutic target for tumor immunotherapy. Immunol Investig. 2017:46(2):172-82.

9. Manieri NA, Chiang EY, Grogan JL. TIGIT: a key inhibitor of the Cancer immunity cycle. Trends Immunol. 2017;38(1):20-8.

10. Blessin NC, Simon R, Kluth M, Fischer K, Hube-Magg C, Li W, MakrypidiFraune G, Wellge B, Mandelkow T, Debatin NF, et al. Patterns of TIGIT expression in normal lymphatic tissue, inflammation and cancer. Disease Markers. 2018. In Press.

11. Johnston RJ, Comps-Agrar L, Hackney J, Yu X, Huseni M, Yang Y, Park S, Javinal V, Chiu H, Irving B, et al. The immunoreceptor TIGIT regulates antitumor and antiviral CD8(+) T cell effector function. Cancer Cell. 2014;26(6):923-37.

12. Chauvin JM, Pagliano O, Fourcade J, Sun Z, Wang H, Sander C, Kirkwood JM, Chen TH, Maurer M, Korman AJ, et al. TIGIT and PD-1 impair tumor antigenspecific CD8(+) T cells in melanoma patients. J Clin Invest. 2015;125(5):2046-58.

13. Kong Y, Zhu L, Schell TD, Zhang J, Claxton DF, Ehmann WC, Rybka WB, George MR, Zeng $\mathrm{H}$, Zheng $\mathrm{H}$. T-cell immunoglobulin and ITIM domain (TIGIT) associates with CD8+ T-cell exhaustion and poor clinical outcome in AML patients. Clin Cancer Res. 2016;22(12):3057-66.

14. Pauken KE, Wherry EJ. TIGIT and CD226: tipping the balance between costimulatory and coinhibitory molecules to augment the cancer immunotherapy toolkit. Cancer Cell. 2014;26(6):785-7.
15. Joller N, Hafler JP, Brynedal B, Kassam N, Spoerl S, Levin SD, Sharpe AH, Kuchroo VK. Cutting edge: TIGIT has T cell-intrinsic inhibitory functions. Immunol. 2011;186(3):1338-42.

16. Blake SJ, Dougall WC, Miles JJ, Teng MW, Smyth MJ. Molecular pathways: targeting CD96 and TIGIT for Cancer immunotherapy. Clin Cancer Res. 2016; 22(21):5183-8.

17. Dougall WC, Kurtulus S, Smyth MJ, Anderson AC. TIGIT and CD96: new checkpoint receptor targets for cancer immunotherapy. Immunol Rev. 2017; 276(1):112-20.

18. Kurtulus S, Sakuishi K, Ngiow SF, Joller N, Tan DJ, Teng MW, Smyth MJ, Kuchroo VK, Anderson AC. TIGIT predominantly regulates the immune response via regulatory T cells. J Clin Invest. 2015;125(11):4053-62.

19. Garber K. Industry 'road tests' new wave of immune checkpoints. Nat Biotechnol. 2017;35(6):487-8.

20. Yu X, Harden K, Gonzalez LC, Francesco M, Chiang E, Irving B, Tom I, Ivelja S, Refino CJ, Clark H, et al. The surface protein TIGIT suppresses T cell activation by promoting the generation of mature immunoregulatory dendritic cells. Nat Immunol. 2009;10(1):48-57.

21. Anderson AC, Joller N, Kuchroo VK. Lag-3, Tim-3, and TIGIT: Coinhibitory receptors with specialized functions in immune regulation. Immunity. 2016:44(5):989-1004.

22. Koh YW, Jeon YK, Yoon DH, Suh C, Huh J. Programmed death 1 expression in the peritumoral microenvironment is associated with a poorer prognosis in classical Hodgkin lymphoma. Tumour Biol. 2016;37(6):7507-14.

23. Greaves P, Clear A, Owen A, labal S, Lee A, Matthews J, Wilson A, Calaminici M, Gribben JG. Defining characteristics of classical Hodgkin lymphoma microenvironment T-helper cells. Blood. 2013;122(16):2856-63.

24. Chetaille B, Bertucci F, Finetti P, Esterni B, Stamatoullas A, Picquenot JM, Copin MC, Morschhauser F, Casasnovas O, Petrella T, et al. Molecular profiling of classical Hodgkin lymphoma tissues uncovers variations in the tumor microenvironment and correlations with EBV infection and outcome. Blood. 2009:113(12):2765-3775.

25. Churchill HR, Roncador G, Warnke RA, Natkunam Y. Programmed death 1 expression in variant immunoarchitectural patterns of nodular lymphocyte predominant Hodgkin lymphoma: comparison with CD57 and lymphomas in the differential diagnosis. Hum Pathol. 2010;41(12):1726-34.

26. Muenst S, Hoeller S, Dirnhofer S, Tzankov A. Increased programmed death-1 + tumor-infiltrating lymphocytes in classical Hodgkin lymphoma substantiate reduced overall survival. Hum Pathol. 2009;40(12):1715-22.

27. Nguyen TT, Frater JL, Klein J, Chen L, Bartlett NL, Foyil KV, Kreisel FH. Expression of TIA1 and PAX5 in classical Hodgkin lymphoma at initial diagnosis may predict clinical outcome. Appl Immunohistochem Mol Morphol. 2016;24(6):383-91.

28. Vardhana $S$, Younes $A$. The immune microenvironment in Hodgkin lymphoma: T cells, B cells, and immune checkpoints. Haematologica. 2016;101(7):794-802.

29. Saraiva M, O'Garra A. The regulation of IL-10 production by immune cells. Nat Rev Immunol. 2010;10(3):170-81.

30. Green MR, Monti S, Rodig SJ, Juszczynski P, Currie T, O'Donnell E, Chapuy B, Takeyama K, Neuberg D, Golub TR, et al. Integrative analysis reveals selective 9p24.1 amplification, increased PD-1 ligand expression, and further induction via JAK2 in nodular sclerosing Hodgkin lymphoma and primary mediastinal large B-cell lymphoma. Blood. 2010;116(17):3268-77.

31. Cedeno-Laurent F, Dimitroff CJ. Galectins and their ligands: negative regulators of anti-tumor immunity. Glycoconj J. 2012;29(8-9):619-25.

32. Poppema S, Kaiserling E, Lennert K. Nodular paragranuloma and progressively transformed germinal centers. Ultrastructural and immunohistologic findings. Virchows Arch B Cell Pathol Incl Mol Pathol. 1979;31(3):211-25.

33. Sattarzadeh A, Diepstra A, Rutgers B, van den Berg A, Visser L. CD57+ T-cells are a subpopulation of T-follicular helper cells in nodular lymphocyte predominant Hodgkin lymphoma. Exp Hematol Oncol. 2015;4:27.

34. Ceeraz S, Nowak EC, Burns CM, Noelle RJ. Immune checkpoint receptors in regulating immune reactivity in rheumatic disease. Arthritis Res Ther. 2014;16(5):469.

35. Tocheva AS, Mor A. Checkpoint inhibitors: applications for autoimmunity. Curr Allergy Asthma Rep. 2017;17(10):72.

36. Nam-Cha SH, Roncador G, Sanchez-Verde L, Montes-Moreno S, Acevedo A, Dominguez-Franjo P, Piris MA. PD-1, a follicular T-cell marker useful for recognizing nodular lymphocyte-predominant Hodgkin lymphoma. Am J Surg Pathol. 2008:32(8):1252-7.

37. Aldinucci D, Gloghini A, Pinto A, De Filippi R, Carbone A. The classical Hodgkin's lymphoma microenvironment and its role in promoting tumour growth and immune escape. J Pathol. 2010;221(3):248-63. 
38. Younes A, Santoro A, Shipp M, Zinzani PL, Timmerman JM, Ansell S, Armand P, Fanale M, Ratanatharathorn V, Kuruvilla J, et al. Nivolumab for classical Hodgkin's lymphoma after failure of both autologous stem-cell transplantation and brentuximab vedotin: a multicentre, multicohort, singlearm phase 2 trial. Lancet Oncol. 2016;17(9):1283-94.

39. Herrera AF, Moskowitz AJ, Bartlett NL, Vose JM, Ramchandren R, Feldman TA, LaCasce AS, Ansell SM, Moskowitz CH, Fenton K, et al. Interim results of brentuximab vedotin in combination with nivolumab in patients with relapsed or refractory Hodgkin lymphoma. Blood. 2018;131(11):1183-94.

40. Goodman A, Patel SP, Kurzrock R. PD-1-PD-L1 immune-checkpoint blockade in B-cell lymphomas. Nat Rev Clin Oncol. 2017;14(4):203-20.

41. Armand P, Shipp MA, Ribrag V, Michot JM, Zinzani PL, Kuruvilla J, Snyder ES, Ricart AD, Balakumaran A, Rose S, et al. Programmed Death-1 blockade with Pembrolizumab in patients with classical Hodgkin lymphoma after Brentuximab Vedotin failure. J Clin Oncol. 2016:34(31):3733-9.

42. Curran MA, Montalvo W, Yagita H, Allison JP. PD-1 and CTLA-4 combination blockade expands infiltrating $T$ cells and reduces regulatory $T$ and myeloid cells within B16 melanoma tumors. Proc Natl Acad Sci U S A. 2010;107(9):4275-80.

43. Hammers HJ, Plimack ER, Infante JR, Rini BI, McDermott DF, Lewis LD, Voss MH, Sharma P, Pal SK, Razak ARA, et al. Safety and efficacy of Nivolumab in combination with Ipilimumab in metastatic renal cell carcinoma: the CheckMate 016 study. J Clin Oncol. 2017;35(34):3851-8.

44. Mirlacher M, Kasper M, Storz M, Knecht Y, Durmuller U, Simon R, Mihatsch MJ, Sauter $\mathrm{G}$. Influence of slide aging on results of translational research studies using immunohistochemistry. Mod Pathol. 2004;17(11):1414-20.

Ready to submit your research? Choose BMC and benefit from:

- fast, convenient online submission

- thorough peer review by experienced researchers in your field

- rapid publication on acceptance

- support for research data, including large and complex data types

- gold Open Access which fosters wider collaboration and increased citations

- maximum visibility for your research: over $100 \mathrm{M}$ website views per year

At $\mathrm{BMC}$, research is always in progress.

Learn more biomedcentral.com/submissions 